JGG 2021;69:226-230

doi: $10.36150 / 2499-6564-N 362$

\title{
The first case of nasal chondromesenchymal hamartoma in an octogenarian: description and literature review
}

\author{
Stefano Millarelli ${ }^{1}$, Fulvio Mammarella ${ }^{1}$, Antonella Loperfido ${ }^{1}$, \\ Francesca Stella ${ }^{2}$, Gianluca Bellocchi ${ }^{1}$ \\ ${ }^{1}$ Otolaryngology Unit, San Camillo Forlanini Hospital, Rome, Italy; ${ }^{2}$ Anatomy and Histology Unit, San \\ Camillo Forlanini Hospital, Rome, Italy
}

Nasal Chondromesenchymal Hamartoma $(\mathrm{NCMH})$ is a rare tumour of the sinonasal tract with a benign clinical behaviour. Locally destructive symptoms may occur.

Due to the extreme rarity of this entity, only a few case reports are present in literature and most of them describe paediatric patients, usually under 12 years. Occasionally it may occur in adults.

Symptoms are usually due to nasal localization, as nasal obstruction or mass effect or local compression caused by the lesion itself, as visual disturbances or facial pain.

Cases described in the adult population are exceedingly rare.

We describe the eldest case reported in literature of NCHM with peculiar features: geriatric patient, septal localization and asymptomatic clinic despite its voluminous size.

The treatment of choice should be radical surgical resection however the best management strategy should be defined after multidisciplinary assessment of frailty in elderly patients.

Received: February 21, 2021
Accepted: March 25, 2021

\section{Correspondence}

Antonella Loperfido

Otolaryngology Unit, San Camillo Forlanini

Hospital, Circonvallazione Gianicolense 87,

00152 Rome, Italy

E-mail: antonella_lop@hotmail.it

How to cite this article: Millarelli S, Mammarella F, Loperfido A, et al. The first case of nasal chondromesenchymal hamartoma in an octogenarian: description and literature review. Journal of Gerontology andGeriatrics2021;69:226-230.https://doi. org/10.36150/2499-6564-N362

(C) Copyright by Società Italiana

di Gerontologia e Geriatria (SIGG)

\section{(c) (1) $(9)$}

\section{OPEN ACCESS}

This is an open access article distributed in accordance with the CC-BY-NC-ND (Creative Commons Attribution-NonCommercial-NoDerivatives 4.0 International) license. The article can be used by giving appropriate credit and mentioning the license, but only for non-commercial purposes and only in the original version. For further information: https://creativecommons.org/licenses/by-nc-nd/4.0/deed.en
Key words: nasal chondromesenchymal hamartoma, geriatric otolaryngology

\section{INTRODUCTION}

Nasal Chondromesenchymal Hamartoma $(\mathrm{NCMH})$ is a rare tumour of the sinonasal tract.

The term NCMH was first introduced by McDermott in 1998 to describe seven paediatric cases of expansive nasal lesions that shared histological mixed features, like mesenchymal hamartoma of the chest, which is mainly composed of chondroid tissue and mesenchymal elements ${ }^{1}$.

Due to the extreme rarity of this entity, only a few case reports are present in literature and most of them describe paediatric patients, usually under 12 years ${ }^{2}$.

Symptoms are usually due to nasal localization (nasal obstruction or mass effect) or local compression caused by the lesion itself (visual disturbances or facial pain). Intracranial and skull base extension may occur.

Cases described in the adult population are exceedingly rare with a maximum age of 70 years so far ${ }^{3}$.

We describe the eldest case of $\mathrm{NCMH}$ in an 87 years old patient. 


\section{CASE REPORT}

An 87 years old man was referred to the Otolaryngology Department of our hospital after the occasional finding of an asymptomatic nasal septal lesion in July 2020.

The lesion was incidentally highlighted at a CT head scan requested after initial geriatric assessment to evaluate the onset of an essential tremor.

The exam revealed a solid neoformation, 47×37×28 mm in size, with a calcific component, destructive in nature, localized at the level of the nasal cavities and septum with extension to the sphenoid sinus, left maxillary sinus, ethmoid cells and left frontal sinus, which caused erosion and architectural subversion of the bone structure (Fig. 1).

The patient underwent a complete otolaryngological evaluation and the anterior rhinoscopy showed the presence of a right septal neoformation associated with a marked left septal deviation.

Therefore, we decided to perform a flexible nasal endoscopy that revealed the presence of a mass most likely generating from the nasal septum with extension to the posterior ethmoid; the lesion was covered with normal mucosa and extended to both nasal cavities causing a subtotal obstruction of the nasal passages. Multiple biopsy samples for histological typing were obtained and no complications occurred during and after the surgical procedure.

The histological report demonstrated fragments of cartilage tissue, partially covered by respiratory mucosa, and organized in nests of variable size, characterized by a cellularity gradient, with peripherally hypercellular areas, and centrally cartilage tissue, with interstitial calcium deposition. No atypia, mitotic figures or areas of necrosis were found, and the final diagnosis was Nasal Chondromesenchymal Hamartoma (Fig. 2).
After multidisciplinary discussion including a full geriatric assessment for frailty, taking into account especially the advanced age of the patient, the anatomical extension and the benign nature of the lesion, the management decision was a wait-and-see approach.

At the moment, after six months from the diagnosis, the patient is following the regular follow-up. The first clinical and radiological evaluation with flexible nasal endoscopy and CT scan performed showed no volumetric increase of the lesion. The patient is currently asymptomatic.

\section{DISCUSSION}

$\mathrm{NCMH}$ is a rare entity with a benign clinical behaviour, usually found in children, without any ethnic prevalence ${ }^{4}$.

The average age of presentation is 9.6 years and the most common localization are the nasal cavities. There are very few adult patients, with only 8 cases reported in English literature ${ }^{2}$.

Some authors have described the role of DICER1 mutation which is correlated with NCHM and dysembryonic sarcoma of the lung and pleura ${ }^{5}$. The DICER1 mutation would lead to a neoplastic syndromic susceptibility with heterogeneous features and with variable risk: high risk for pleuropulmonary blastoma, ovarian stromal tumor, Sertoli cell tumor, gynandroblastoma; low risk for cystic nephroma and thyroid neoplasms; rare risk for medulloepithelioma, embryonal rhabdomyosarcoma (ERMS, botryoid type), renal sarcoma and pituitary blastoma ${ }^{6}$. In this context, a peculiar feature of $\mathrm{NCHM}$ would be the early presentation compared to other neoplasms; for this reason, it is important to know the potential associations and carry out the appropriate exclusion investigations ${ }^{\text {? }}$.

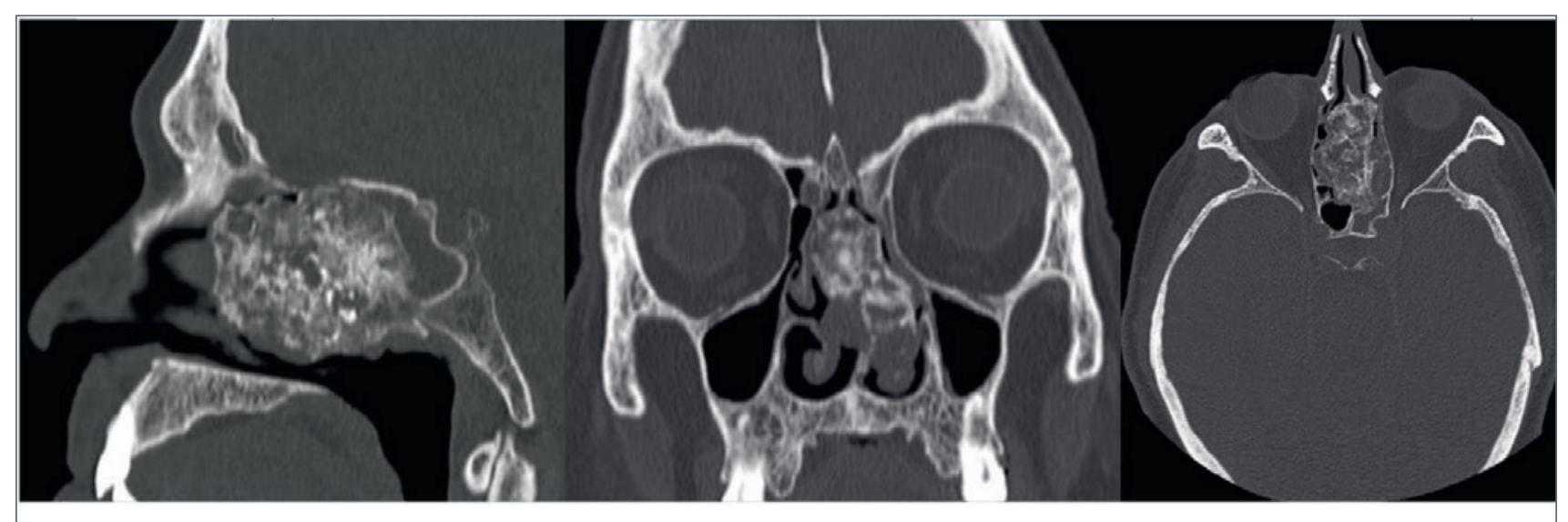

Figure 1. CT head scan, 1A- Sagittal view, 1B- Coronal view, 1C- Axial view: solid neoformation, 47x37x28 mm in size, with a calcific component, destructive in nature, placed at the level of the nasal cavities and septum with extension to the paranasal sinuses. 


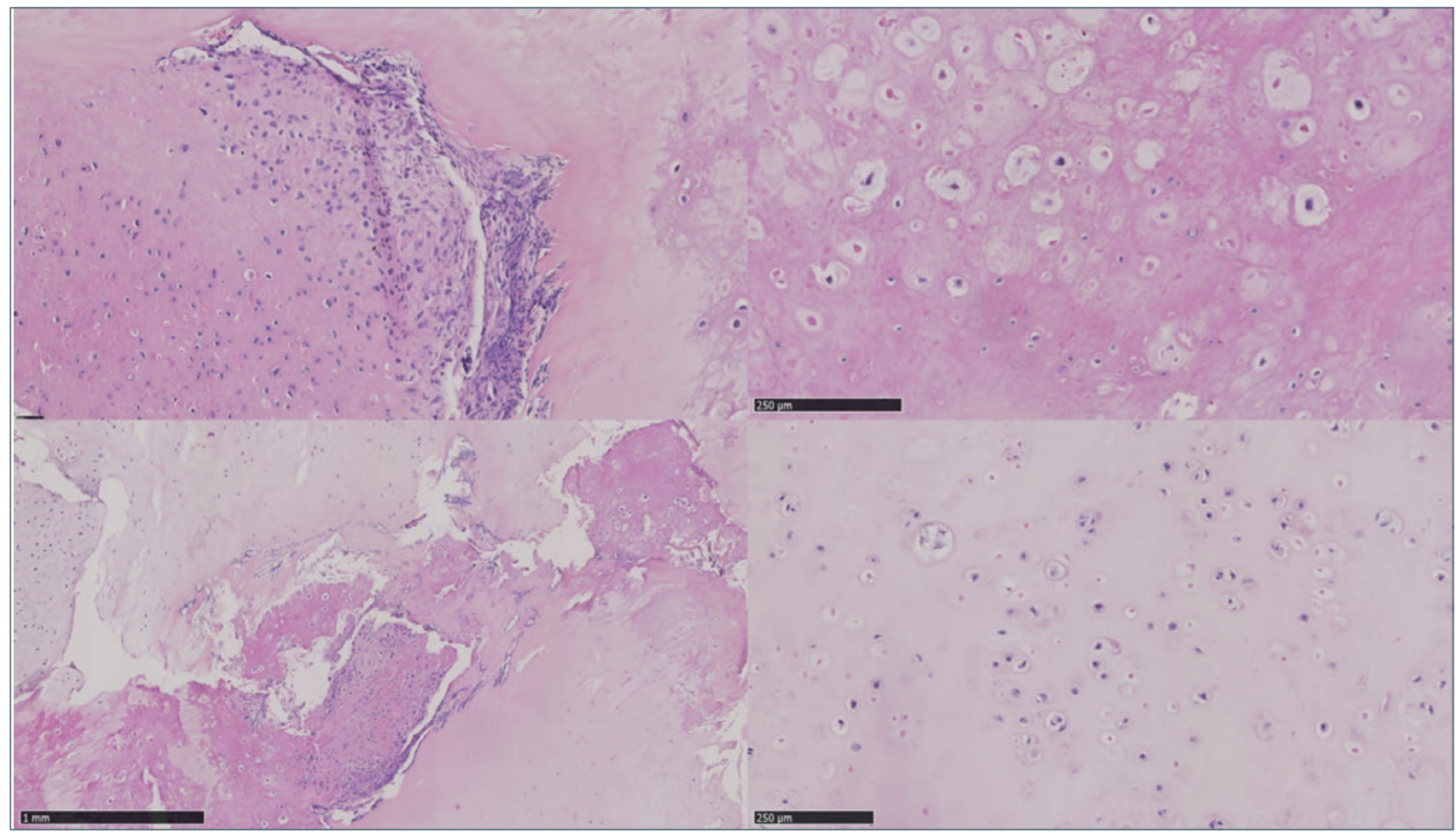

Figure 2. Biopsy showing fragments of cartilage tissue, partially covered by respiratory mucosa, and organized in nests of variable size, characterized by a cellularity gradient, with peripherally hypercellular areas, and centrally cartilage tissue, with interstitial calcium deposition.

The usual clinical presentation in children consists of nasal obstruction, mass effect, headache, facial pain and ocular signs due to the involvement of the orbit such as strabismus, esotropia, hypertelorism, enophthalmos, ophthalmoplegia and diplopia ${ }^{8,9}$. Oral symptoms secondary to extension into the oral cavity have been described ${ }^{10}$.

Less common symptoms are recurrent sinusitis, rhinorrhoea, otitis media, epistaxis, toothache, hyposmia and very rarely hydrocephalus or other manifestations secondary to intracranial extension ${ }^{11}$.

On the contrary, in adults, the clinical presentation is typically smouldering with the onset of a slow growing, painless, expansive neoformation in the nasal cavity, sometimes with a local erosive behaviour on the maxillary region, for such reason, at a first clinical evaluation, it may be misdiagnosed as malignant neoplasms ${ }^{3}$.

Pre-operative imaging usually shows a lesion involving nose, paranasal sinuses, sometimes with extension to the orbital region and rarely to intracranial district.

The typical appearance on CT is a non-encapsulated lesion, with a heterogeneous appearance and with poorly defined margins and soft tissue density with solid elements, cysts or intralesional calcifications (in $50 \%$ of cases). Also at MRI scan the appearance is heterogeneous even though margins of the lesion are better defined than on $\mathrm{CT}^{12}$.
Differential clinical diagnosis should exclude all other sinonasal lesions: septal papilloma, inverted papilloma, sinonasal carcinoma, mucocele of the sinus, nasoethmoid encephalocele, chondrosarcoma, paranasal lymphoma and rhabdomyosarcoma. A biopsy with the histological diagnosis is mandatory to define the correct subsequent management.

The slow growth of the lesion, the presence of an active phenotype only in adulthood and the local response to a chronic inflammatory insult, are possible causes to explain the finding of $\mathrm{NCMH}$ also in adult subjects. Such literature data lead to re-consider NCHM among (rare) nasal lesions of adulthood and in rare cases, also in geriatric patients ${ }^{4}$. Moreover, the $4^{\text {th }}$ edition of the $\mathrm{WHO}$ classification of Head and Neck tumors, defined NCHM as tumor-like entity included as provisional diagnoses or discussed in the setting of the differential diagnosis of nasal cavity, paranasal sinuses, and skull base ${ }^{13}$.

Surgical approach is not always necessary, like reported in our case, but a strict clinical and radiological monitoring is recommended because of the rare chance of malignant transformation ${ }^{14}$.

There are different histological subtypes of hamartomatous lesions: angiomatous, lipomatous, chondroid, neurogenic and epithelial variety, usually defined by the widely represented tissue. $\mathrm{NCMH}$ has the same 
histological features of other mesenchymal hamartomas, as the presence of chondroid tissue mixed with calcified areas, myxoid stroma and mesenchymal elements ${ }^{15}$.

Due to the rarity of NCHM, there are currently no management guidelines. Complete excision is recommended to prevent volumetric increase or local recurrence, although it is not always possible, especially in cases with intracranial extension or in elderly patients.

A role of paramount importance is played by both frailty and measures of independence in activities of daily living because they have turned out to be predictors of perioperative complications and length of hospital stay in patients undergoing head and neck cancer surgery ${ }^{16,17}$.

There is a growing body of evidence highlighting the urgent need for a closer multidisciplinary evaluation between otolaryngologists and geriatricians leading towards the field recently defined "Geriatric Otolaryngology" 18,19 .

In conclusion, we described the eldest case reported in literature of $\mathrm{NCHM}$ with peculiar features: geriatric patient, septal localization and asymptomatic clinic despite its voluminous size.

The treatment of choice should be radical surgical resection however the best management strategy should be defined after multidisciplinary assessment of frailty in elderly patients.

\section{Ethical consideration}

The patient gave explicit consent for publication of this case.

\section{Acknowledgement}

None.

\section{Funding}

None.

\section{Conflict of interest}

The authors declare to have no conflict of interest.

\section{Author contributions}

Millarelli S: conceptualization

Mammarella F: literature review

Loperfido A: manuscript drafting

Stella S: data collection

Bellocchi G: final approval

\section{References}

1 McDermott MB, Ponder TB, Dehner LP. Nasal chondromesenchymal hamartoma: an upper respiratory tract analogue of the chest wall mesenchymal hamartoma. Am J Surg Pathol 1998;22:425-33. https://doi. org/10.1097/00000478-199804000-00006
2 Mason KA, Navaratnam A, Theodorakopoulou E, et al. Nasal Chondromesenchymal Hamartoma (NCMH): a systematic review of the literature with a new case report. J Otolaryngol Head Neck Surg 2015;44:28. https://doi. org/10.1186/s40463-015-0077-3

3 Mirchia K, Naous R. Nasal chondromesenchymal hamartoma: rare case report in an elderly patient and brief review of literature. Case Rep Pathol 2018;2018:5971786. https://doi.org/10.1155/2018/5971786

4 Ünal A, Kum RO, Avcı Y, et al. Nasal chondromesenchymal hamartoma, a rare pediatric tumor: case report. Turk J Pediatr 2016;58:208-211. https://doi.org/10.24953/ turkjped.2016.02.014

5 Stewart DR, Messinger Y, Williams GM, et al. Nasal chondromesenchymal hamartomas arise secondary to germline and somatic mutations of DICER1 in the pleuropulmonary blastoma tumor predisposition disorder. Hum Genet 2014;133:1443-1450. https://doi.org/10.1007/ s00439-014-1474-9

6 Merideth MA, Harney LA, Vyas N, et al. Gynecologic and reproductive health in patients with pathogenic germline variants in DICER1. Gynecol Oncol 2020;156:647-653. https://doi.org/10.1016/j.ygyno.2019.12.037

7 Johnson C, Nagaraj U, Esguerra J, et al. Nasal chondromesenchymal hamartoma: radiographic and histopathologic analysis of a rare pediatric tumor. Pediatr Radiol 2007;37:101-104. https://doi.org/10.1007/ s00247-006-0352-6

8 Moon SH, Kim MM. Nasal chondromesenchymal hamartoma with incomitant esotropia in an infant: a case report. Can J Ophthalmol 2014;49:e30-32. https://doi. org/10.1016/j.jcjo.2013.11.011

9 Kato K, ljiri R, Tanaka Y, et al. Nasal chondromesenchymal hamartoma of infancy: the first Japanese case report. Pathol Int 1999;49:731-736. https://doi. org/10.1046/j.1440-1827.1999.00933.x

10 Cho YC, Sung IY, Son JH, et al. Nasal chondromesenchymal hamartoma: report of a case presenting with intraoral signs. J Oral Maxillofac Surg 2013;71:72-76. https://doi. org/10.1016/j.joms.2012.03.020

11 Nakaya M, Yoshihara S, Yoshitomi A, et al. Endoscopic endonasal excision of nasal chondromesenchymal hamartoma with intracranial extension. Eur Ann Otorhinolaryngol Head Neck Dis 2017;134:423-425. https://doi. org/10.1016/j.anorl.2016.05.014

12 Wang T, Li W, Wu X, et al. Nasal chondromesenchymal hamartoma in young children: CT and MRI findings and review of the literature. World J Surg Oncol 2014;12:257. https://doi.org/10.1186/1477-7819-12-257

13 Thompson LDR, Franchi A. New tumor entities in the $4^{\text {th }}$ edition of the World Health Organization classification of head and neck tumors: nasal cavity, paranasal sinuses and skull base. Virchows Arch 2018;472:315-330. https://doi. org/10.1007/s00428-017-2116-0 
14 Li Y, Yang QX, Tian XT, et al. Malignant transformation of nasal chondromesenchymal hamartoma in adult: a case report and review of the literature. Histol Histopathol 2013;28:337-344. https://doi.org/10.14670/HH-28.337

15 Norman ES, Bergman S, Trupiano JK, et al. Nasal chondromesenchymal hamartoma: report of a case and review of the literature. Pediatr Dev Pathol 2004;7:517-520. https://doi.org/10.1007/s10024-004-1003-2

16 Goldstein DP, Sklar MC, de Almeida JR, et al. Frailty as a predictor of outcomes in patients undergoing head and neck cancer surgery. Laryngoscope 2020;130:e340-e345. https://doi.org/10.1002/lary.28222
17 Pitts KD, Arteaga AA, Stevens BP, et al. Frailty as a predictor of postoperative outcomes among patients with head and neck cancer. Otolaryngol Head Neck Surg 2019;160:664671. https://doi.org/10.1177/0194599818825466

18 Skalska A, Składzień J. Challenges of modern medicine - geriatric otolaryngology or the advantages of cooperation between an otolaryngologist and a geriatrician. Otolaryngol Pol 2018;73:1-5. https://doi. org/10.5604/01.3001.0012.7218

19 Mirza N, Lee JY. Geriatric otolaryngology. Otolaryngol Clin North Am 2018;51:17-18. https://doi.org/10.1016/j. otc.2018.04.002 